\title{
Cutaneous Presentation of Neuroblastoma in 8 Months Old Boy: A Rare Case Report
}

\author{
Mahendra Singh ${ }^{1}$, Lubna Khan ${ }^{2 *}$, Swetlana Sachan ${ }^{3}$, Vandana Mishra ${ }^{4}$, Anveksha Sachan ${ }^{3}$ \\ ${ }^{1}$ Professor \& Head, Department of Pathology, GSVM Medical College, Kanpur, India \\ ${ }^{2}$ Professor, Department of Pathology, GSVM Medical College, Kanpur, India \\ ${ }^{3}$ Junior Resident III, Department of Pathology, GSVM Medical College, Kanpur, India \\ ${ }^{4}$ Assistant Professor, Department of Pathology, GSVM Medical College, Kanpur, India
}

*Address for Correspondence: Dr. Lubna Khan, Professor, Department of Pathology, GSVM Medical College, Kanpur, India

E-mail: swetlana.sachan@gmail.com

Received: 30 Apr 2019/ Revised: 16 June 2019/ Accepted: 02 July 2019

\begin{abstract}
Background: Neuroblastoma is the neurogenic, extracranial solid tumor of infancy and children emerging anywhere along with the peripheral sympathetic nervous system.

Methods: An eight months old boy presented with chief complaints of sub-cutaneous non-tender nodule on the flexor aspect of forearm, pain and fullness of abdomen, emesis, mild bone pain. Complete blood profile and other biochemical parameter were within normal limits.

Results: Fine needle aspiration cytology revealed tumour cells having high nucleo-cytoplasmic ratio bare nuclei, which were round to oval in shape. Homer wright rosette arrangement was formed by tumor cells that were radially arranged in a circle. The neuropil, which was stained as eosinophilic material was seen in the center of rosette arrangement.

Conclusions: Hence on the basis of age and rare cutaneous presentation along with cytological findings; clinical features and radiological findings we can provide a diagnosis of metastasis neuroblastoma.
\end{abstract}

Key-words: Extracranial, Eosinophilic fibrillary material, Homer wright rosette, Neuropil, Neuroblastoma

\section{INTRODUCTION}

Neuroblastoma is the third most common neurogenic, an extracranial solid tumor of infancy and children emerging anywhere along the peripheral sympathetic nervous system ${ }^{[1]}$. It accounts for $8-10 \%$ of all cancers in children [2]. Nearly $50 \%$ of neuroblastomas were diagnosed in children younger than 5 years of age ${ }^{[3]}$. Its diagnosis becomes poor and poor as the age advances. It was sporadic or non-familial in origin ${ }^{[4]}$.

They arise from primitive cells and are seen in the adrenal medulla and sympathetic ganglia of the sympathetic nervous system. These aggressive cells begin to grow uncontrollably.

\section{How to cite this article}

Singh M, Khan L, Sachan S, Mishra V, Sachan A. Cutaneous Presentation of Neuroblastoma in 8 Months Old Boy: A Rare Case Report. SSR Inst. Int. J. Life Sci., 2019; 5(4): 2365-2368.

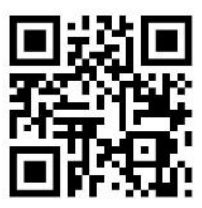

Neuroblastomas may lead to signs such as swelling in the face, neck, arms and upper chest, headaches, dizziness, changes to consciousness, drooping eyelids and small pupils. They may also lead to signs of paraneoplastic syndromes that include constant diarrhea, fever, high blood pressure (causing irritability), rapid heartbeat, flushing of the skin, and sweating. Because neuroblastomas consist of embryonic cells, they were especially common among small children: up to $90 \%$ of the patients are younger than six years old ${ }^{[5]}$.

\section{CASE REPORT}

An 8 months old boy was admitted in the Department of Pathology, GSVM Medical College Kanpur in the month of March to April, 2019 with a subcutaneous non-tender nodule on the flexor aspect of forearm for 2 months, with chief complaints of pain in abdomen, fullness of abdomen, emesis, weight loss, anorexia, mild bone pain. Complete blood profile was within normal limits and other biochemical parameters were also within normal 
limits. Multi slice spiral C.T. of the abdomen showed well defined, lobulated heterogeneously enhancing mass lesion in relation to the superomedial aspect of the right kidney with few calcification and encasement of abdominal vessels with skeletal metastasis suggesting neuroblastoma. Ultrasound of the patient revealed a solid, isoechoic to hypoechoic mass $3 \times 2 \mathrm{~cm}$ in diameter was located near the right adrenal gland.

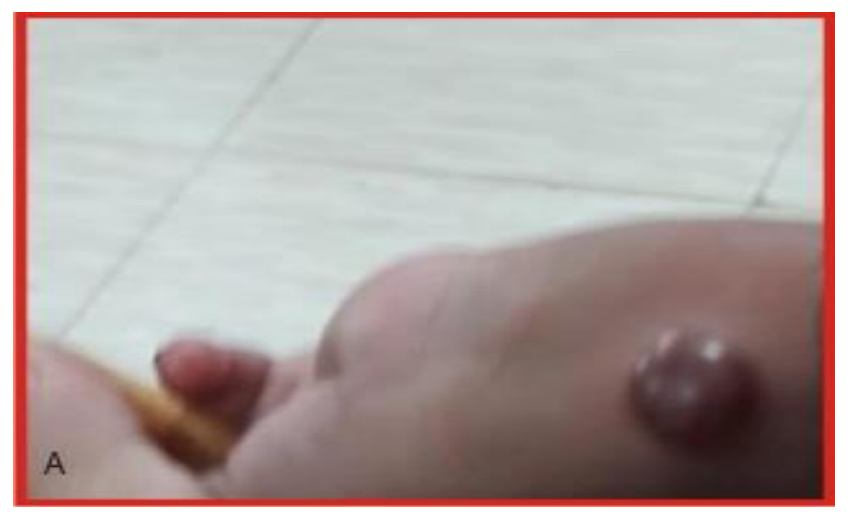

Fig. 1: Red cutaneous nodular swelling in the flexor aspect of forearm
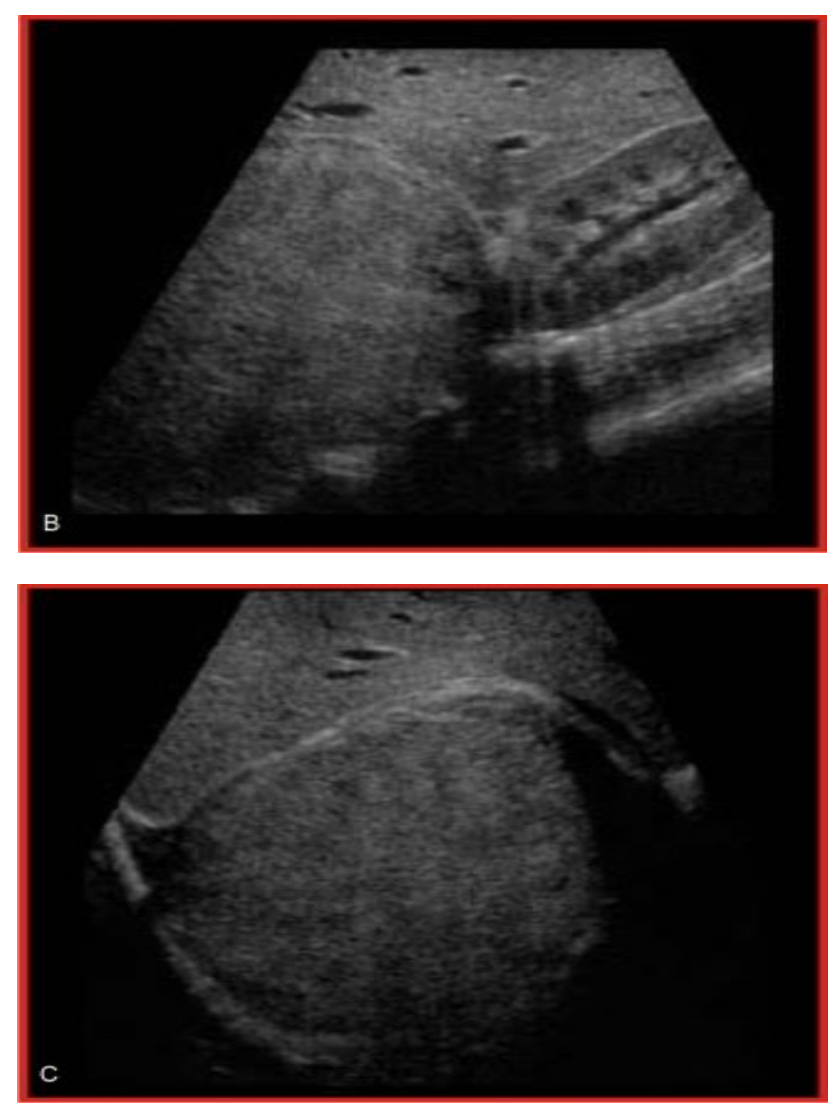

Fig. 2 (B,C): Ultrasonography reveals well defined isoechoic to hypoechoic rounded mass lesion noted in right suprarenal region with sharply defined margin with upper pole of kidney and posterior segment of right lobe of liver. No evidence of any internal echogenic foci or cystic degeneration

\section{Fine needle aspiration cytology}

On Aspiration- Blood mixed material was obtained.

Microscopic examination- Good cellularity smear revealed tumor cells having bare nuclei which were round to oval in shape. Homer wright rosettes arrangements were formed by tumor cells that are radially arranged in a circle. The neuropil (eosinophilic fibrillary material) was seen in the center of rosette arrangement. Red blood cells were seen around tumor cells. These tumor cells showed increased nucleocytoplasmic ratio and their nuclei were round to oval in shape with anisokaryosis, nuclear chromatin was granular.
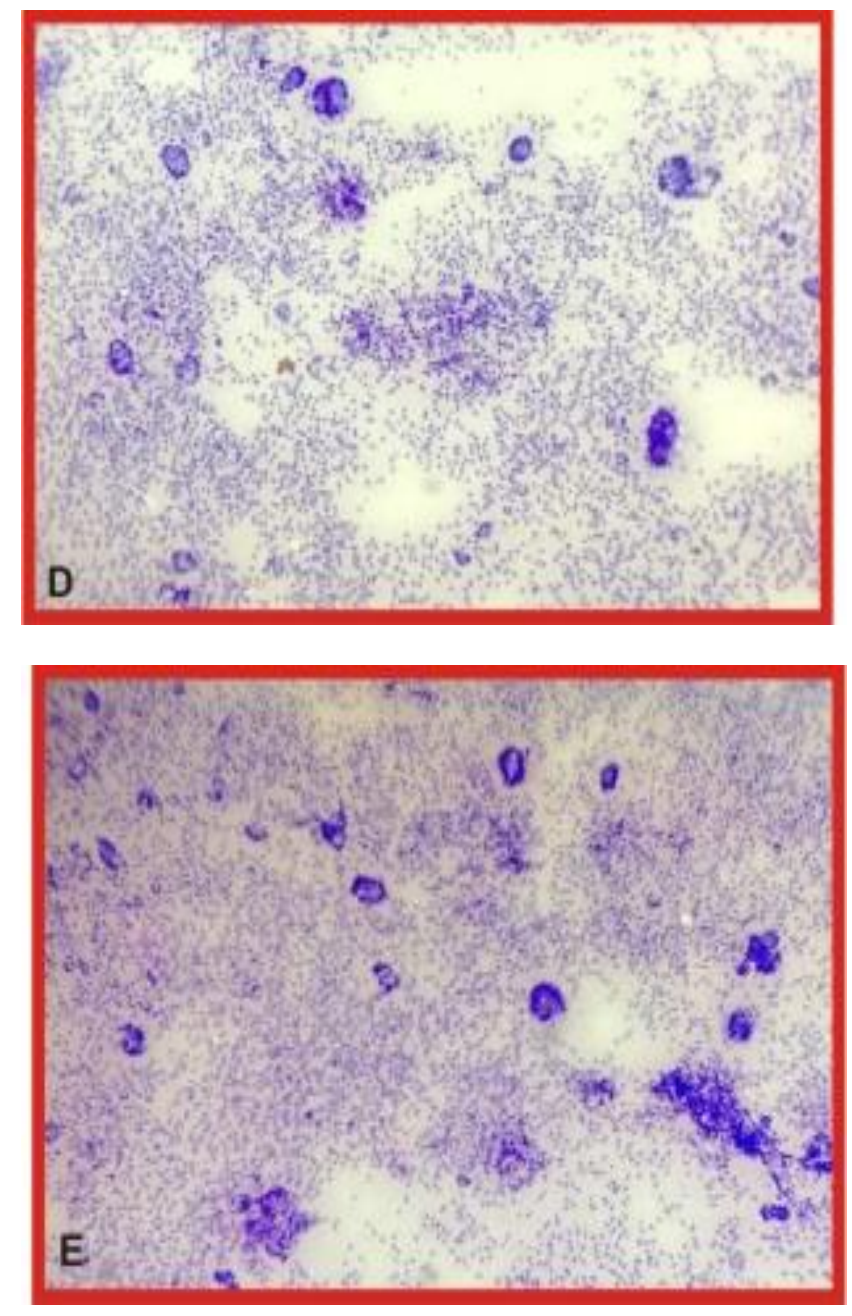

Fig. 3 (D,E): On 10x magnification showing scattered as well as clusters of small round neuroblastic cells, few of them forming rosette like structure. Background shows eosinophilic fibrillary material 

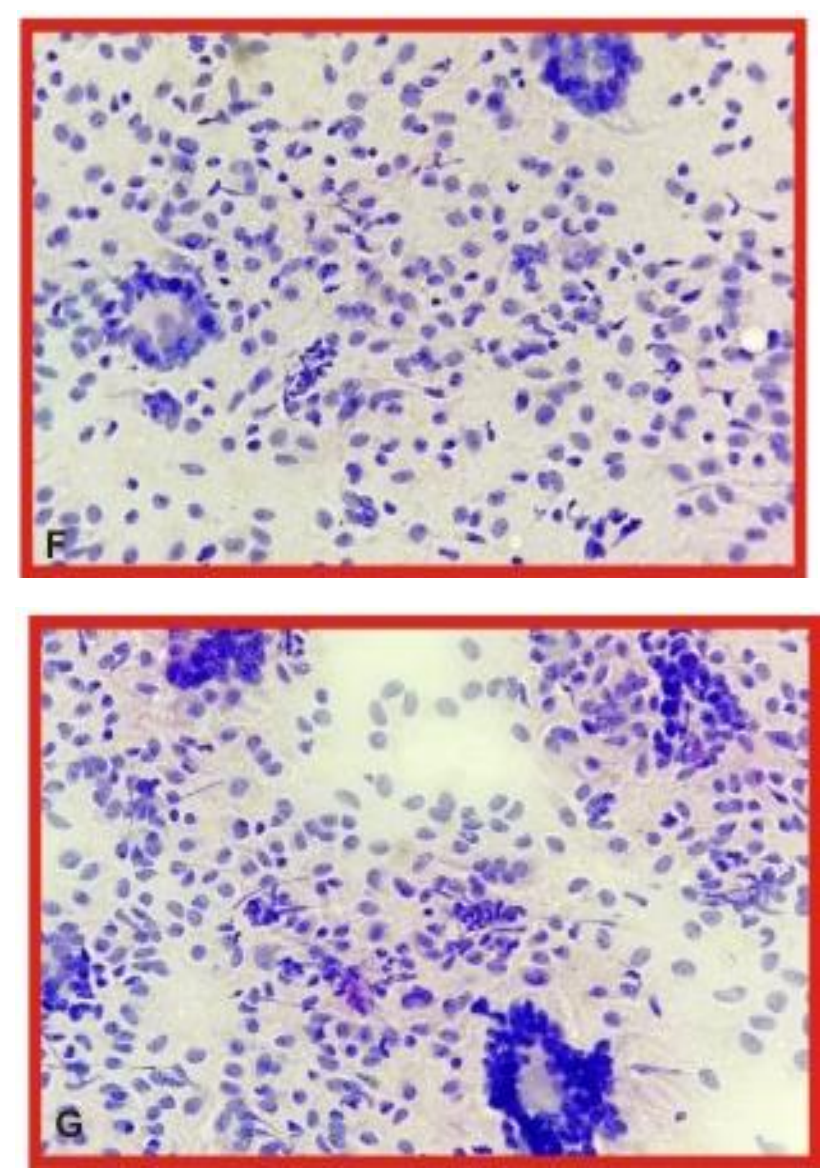

Fig. 4 (F,G): On 40x magnification showing clusters of round to oval cells forming rosette like structure and

centre of these rosettes are filled with neuropil

(Eosinophilic material). These cells are having round monomorphic nuclei with granular chromatin and with scant cytoplasm

\section{DISCUSSION}

The median age of diagnosis was 22 months and $80 \%$ of children are diagnosed $<4$ years of age ${ }^{[2]}$. Clinical presentation of Neuroblastoma reflects the tumor's primary location and extent of metastatic decrease if presented. The most common primary for Neuroblastoma is abdomen, which may metastasize to bone, lymph node, liver, intracranial site, orbital sites, lungs and central nervous system ${ }^{[6]}$.

Clinically, the Neuroblastoma presented the proptosis, periorbital ecchymosis, abdominal distension, bone pain, fever, anaemia, hypertension, subcutaneous nodule, and watery diarrhea [7]. In children, these signs and symptoms were more severe and widespread (as it metastasizes rapidly), whereas in adolescents there was a greater frequency of metastasis to lung or brain ${ }^{[7-9]}$. Multiple cytogenetic abnormalities, amplification of the n-myconcogene and changes in normal diploid chromosomal content have been identified as a part of the disease process ${ }^{[10]}$.

Neuroblastoma is one among the thousands of such conditions diagnosed so far, which is characterized by rapid metastasis leading to proptosis and abdominal distension. In children these signs and symptoms are more severe and widespread as it metastasize rapidly whereas in adolescents, where was a greater frequency of metastasis to lung or brain ${ }^{[11,12]}$. Surgical therapy is the preferred treatment for stage 1-2A patients, while chemotherapy and radiotherapy are usually given to stage 2B-3-4 patients ${ }^{[13]}$.

Neuroblastoma has a very broad spectrum of clinical behavior which ranges from spontaneous regression to maturation of a benign ganglioneuroma, or aggressive disease with metastasis leading to death. The best prognosis is awarded to newborn followed by infant and toddler. The children over age five are subjected to poor prognosis ${ }^{[14]}$. The chemo-resistant and relapsed cases have poor prognosis ${ }^{[15]}$.

\section{CONCLUSIONS}

The prognosis of the patient with Neuroblastoma depends on their age and stage of disease at the time of diagnosis. On the basis of FNAC, clinical and radiological features, we can provide a definite diagnosis of neuroblastoma. Neuroblastoma has a very broad spectrum of clinical behavior, which ranges from spontaneous regression to maturation of a benign ganglioneuroma, or aggressive disease with metastasis leading to death. In low-risk patients, baseline treatment was surgical resection with chemotherapy. For high-risk pediatric patients, aggressive surgical resection, high dose chemotherapy, radiation therapy, stem cell therapy and immunologic therapy is recommended.

\section{ACKNOWLEDGMENTS}

All authors were thankful to the Department of Pathology, GSVM Medical College Kanpur, India for help in writing the case report.

\section{CONTRIBUTION OF AUTHORS}

Research concept- Dr. Swetlana Sachan

Research design- Dr. Lubna Khan

Supervision- Dr. Lubna Khan

Materials- Dr. Vandana Mishra

Data collection- Dr. Anveksha Sachan

Data analysis and interpretation- Dr. Lubna Khan 
Literature search- Dr. Swetlana Sachan

Writing article- Dr. Anveksha Sachan

Critical review- Dr. Mahendra Singh

Article editing- Dr. Swetlana Sachan

Final approval- Dr. Swetlana Sachan

\section{REFERENCES}

[1] Kushner BH, Kramer K, Modak S. Neuaroblastoma in adolescents and adults: The memorial sloankettering experience. Med Pediatr Oncol., 2003; 41(6): 508-15. doi: 10.1002/mpo.10273.

[2] Lee KL, Ma JF, Shortlife LD. Neuroblastoma management recurrence and follow up. Urol. Clin. North Am., 2003; 30(4): 881-90.

[3] Podda MG, Luksch R, Polastri D, Gandola L, Piva L, et al. Neuroblastoma in patients over 12 years old: A 20-year experience at the National Cancer Institute of Milan. Tumori, 2010; 96(5): 684-89.

[4] Ritesh R, Ashital R. Neuroblastoma is early childhood: A rare case report and review of literatures. Contemp. Clin. Dent., 2016; 7(3): 401-04. doi: 10.4103/0976-237X.188579.

[5] Yanik F, Karamustafaoglu YA, Yoruk Y. A rare mediastinal occurrence of neuroblastoma in an adult: case report. Sao. Paulo. Med. J., 2019; 137(1): 104-06. doi: 10.1590/15163180.2017.0160140617.

[6] DuBois SG, Kalika Y, Lukens JN, Brodeur GM, Seeger $R C$, et al. Metastatic sites in stage IV and IVs Neuroblastoma correlates with age, Tumor biology and survival. J. Pediatr. Hematol. Oncol., 1999; 21(3): 181-89.

[7] Citak C, Karadeniz C, Dalgic, Ogu Z. Intestinal lymphangiectasia on a first presentation of neuroblastoma. Pediatr. Blood Cancer, 2006; 46(1): 105-57. doi: 10.1002/pbc. 20530.
[8] Bourdeaut F, deCarli, Timsit S, Caze C. VIP hyperexcretion as primary or secondary syndrome in neuroblastoma: A retrospective study by the Societe Transcoise des Cancers de I'Enfant (SFCE). Pediatr. Blood cancer, 2003; 52(5): 585-90.

[9] Mahoney NR, Liu GT, Menacker SJ, Wilson MC, Hogarty MD, et al. Pediatric harner syndrome: Etiologies and values of imaging and urine studies to detect neuroblastoma and other responsible may lesions. Am. J. Ophthalmol., 2006; 142(4): 651-59.

[10]Schilling FH, Spix C, Berthold F, Erttmann R, et al. Neuroblastoma screening at one year of age. N. Engl. J. Med., 2002; 346: 1647-5103.

[11]Citak C, Karadeniz C, Dalgic B, Oguz A, Poyraz A, et al. Intestinal lymphangiectasia as a first manifestation of neuroblastoma. Pediatr. Blood Cancer, 2006; 46(1): 105-07.

[12]Bourdeaut F, De Carli E, Timsit S, Coze C, Chastagner $P$, et al. VIP hypersecretion as primary or secondary syndrome in neuroblastoma: A retrospective study by the Societe Francaise des Cancers de I' Enfant (SFCE). Pediatr. Blood Cancer, 2009; 52(5): 585-90. doi: 10.1002/pbc.21912.

[13] George I, Dimitrios F, loannis F, Sofia P, Athanasios K. A Rare Adult Case with Neuroblastoma. J. Tumor, 2014; 2(10); 481-86.

[14]Shimada $H$, Umehara $S$, Monobe $Y$, Hachitanda $Y$, Nakagawa $A$, et al. International neuroblastoma pathology lassification for prognostic evaluation of patients with peripheral neuroblastic tumors: A report from the Children's Cancer Group. Cancer, 2001; 92(9): 2451-61.

[15]Yuan LQ, Wang JH, Zhu K, Yang M, Gu WZ, et al. A highly malignant case of neuroblastoma with substantial increase of single-nucleotide variants and normal mismatch repair system; Medicine (Baltimore), 2017; 96(50): e8845. 